\title{
Supervisor relationships, teamwork, role ambiguity and discretionary power: Nurses in
}

\section{Australia and the UK}

There is a shortage of nurses in many OECD countries (OECD, 2006). Additionally, replacement costs are high and turnover negatively affects morale as well as patient outcomes (Hayes, O'Brien-Pallas, Duffield, Shamian, Buchan \& Hughes, 2006). Consequently, healthcare management needs to ensure that the retention of skilled nurses is a priority, and previous research suggests that supervisor-subordinate relationships are important predictors of organisational commitment and turnover (Brunetto, Farr-Wharton \& Shacklock, 2010; 2011 in press; Cohen, 2006; Tauton, Boyle \& Woods, 1997) as well as positive patient outcomes (Rafferty, Clarke, Coles, Ball \& James, 2007). Moreover, nurses’ ability to learn via teamwork has been identified as an effective means of reducing role ambiguity and thereby improving patient outcomes (Drach-Zahavy \& Pud, 2010).

However, the provision of healthcare has changed significantly as a result of rationalizing over the past thirty years and the outcomes include flattened hierarchical management structures, increased workloads for nurses and increased managerial control for supervisors (Bolton, 2003; 2004; Kirkpatrick, Ackroyd \& Walker, 2004). Research suggests that these outcomes have negatively affected nurses' supervisor-subordinate relationships (Bolton, 2003; 2004; Brunetto, Farr-Wharton \& Shacklock, 2010) as well as nurses' perceptions of their discretionary power (Ackroyd, Kirkpatrick \& Walker, 2007), which are also likely to have negatively affected commitment (Spritizer, 1995; Laschinger, Finegan, Shamian \& Wilk, 2004). Importantly, past research also suggests that employees’ perceptions of discretionary power are vital in staff shortage work environments (Scotti, Harmon \& Behson, 2007).

However, Carroll and Steane (2002) argue that the implementation of recent reforms has affected Australian public sector employees more than those in other countries, by 
increasing managerial control leading to reductions in employees' perceptions of discretionary power. Yet, there remains a void in the literature within the nursing context comparing the links between supervisor-subordinate relationships, teamwork, role ambiguity in relation to patients and in turn, discretionary power across public and private sector workplaces. Further, although Mrayyan (2005) argues that there is a belief that private sector healthcare providers are better than the public sector at retaining their nurses, there have been few studies comparing the public-private domain.

In terms of similarities and differences between UK and Australia, the findings suggest there are probably more similarities than differences. For example, in terms of Hofstede's (1980) five dimensions of cross-cultural characteristics, developed across many different countries, Australia and UK are reported as similar in national culture. In terms of all five dimensions - power distance (measuring the degree to which unequal power distribution is tolerated in the society), individualism (the degree to which there is social integration), masculinity (the degree to which authority and performance are preferred), uncertainty avoidance (measuring a society's tolerance for uncertainty in the future) and long-term orientation (the extent to which a society focuses on the long term) - Australia and the UK are in the same categories. The biggest difference is in relation to uncertainty avoidance, because according to Hofstede, Australia has a slightly lower tolerance for uncertainty and therefore has more rules and regulations in place controlling behaviour - at least in theory. While there have been some criticisms of Hofstede's work, his measures remain the most widely used in both academic and practical context (Bond, 2002). The implication of Hofstede's research identifying that Australia and the UK are similar in culture, is that any differences in nurses' satisfaction with their supervisor should therefore not reflect cultural differences. Instead, any differences are more likely to reflect differences in management practices and/or working conditions. 
Consequently, the study examines the convergence and divergence between countries, by investigating the differences for nurses in the association of supervisor-nurse relationships, teamwork, role ambiguity and discretionary power between public and private sector hospitals, and between Australia and UK. Such information is important because it highlights similarities and differences in management practices across UK and Australian public and private sector hospitals. The following research questions were therefore developed to guide the data collection:

RQ1: What is the relationship between nurses' satisfaction with their supervisorsubordinate relationships and teamwork, plus nurses' perceptions of role ambiguity (in relation to patients) and discretionary power?

RQ2: In Australia and UK, is the relationship the same between nurses' satisfaction with their supervisor-subordinate relationships and teamwork, plus nurses' perceptions of role ambiguity (in relation to patients) and discretionary power?

RQ3: Across public and private healthcare system, is the relationship the same between nurses' satisfaction with their supervisor-subordinate relationships and teamwork, plus nurses’ perceptions of role ambiguity (in relation to patients) and discretionary power?

This paper provides a review of the relevant literature from which the hypotheses emerged. The samples and methods used to test the hypotheses and address the research questions are described nest. Following this, the results are presented and the discussion section then identifies pattern-matching with relevant past research and implications for healthcare managers. Finally, the paper concludes and offers suggestions for future research.

\section{Leader-Member Exchange Theory}


Leader Member Exchange Theory (LMX) provides a means of examining the supervisorsubordinate relationship. The theory assumes that supervisors treat employees differently and consequently, only some employees experience high quality 'social exchanges' with their supervisors. These employees benefit from the exchange of support, information, trust, participation in decision-making and respect (Mueller \& Lee 2002). Effective LMX relationships are also beneficial, because by promoting exchanges of information and support, they also have the added benefit of promoting valuable learning that occurs as a byproduct of engaging effectively in teamwork, which in turn, promotes greater participation in decision-making within work teams (Bindi et al., 2008). Such an environment is likely to reduce role ambiguity in relation to patients (Jolke \& Duhan, 2000; Rhoads, Singh \& Goodell, 1994) and this enhances nurses’ perceptions of empowerment (Yrie, Hartman, \& Galle, 2003; Yukl, 2006).

However, the LMX relationship is likely to have been affected by public sector reforms in the UK, USA, Australia and NZ that have increased the discretionary power of supervisors to control the work practices of nurses. In these countries, nurses have experienced standardization in service delivery, based on resource utilization and work intensification (Ackroyd, et al., 2007). In particular, public sector nurses have experienced increased workloads, poorer working conditions, inflexible scheduling, increased intensity of work, loss of work autonomy and increased accountability - especially in relation to increased record-keeping and data collection (Adcroft \& Willis, 2005; Brunetto \& FarrWharton, 2006; 2007, Brunetto, et al., 2010; 2011, in press).

According to Ackroyd et al. (2007), nurses' work environments are to some extent dependent on their supervisors' ability to reconcile the organisational demands for increased efficiency with the nursing profession demands to nurture the interests of their nurses. Nurses have specific beliefs, values and aspirations from their nursing profession and nurse 
supervisors have specific responsibilities to ensure the professional development of nurses (Brock, Powell \& Hinings, 1999; Friedson, 2001; Maynard-Moody \& Mushero, 2003). Consequently, this paper examines whether there are similarities and differences in nurse supervision between public and private sector hospitals, and between Australia and the UK.

\section{Teamwork}

Teamwork is often considered a non-formal (incidental) means of learning (Marsick \& Watkins, 2001) because it occurs, for example, when nurses are working in teams on the same shift, watching the results of trial and error in medicating a patient and examining and/or challenging assumptions and beliefs. Teamwork is also the avenue where the transfer of knowledge learnt at training can be passed on to those who have not attended the training (Koopman, Doornbos, \& van Eekelen, 2006). Effective teamwork is linked to improving patient safety (Vincent, 2007), especially for the less experienced nurses (Wain, 1993) and therefore has a positive impact in reducing role ambiguity. However, past research suggests that the role of the supervisor is critical in determining the quality of teamwork and only when supervisors role-model the sharing of information, resources and support will their subordinates do likewise (Edmondson, 2003; Ellemers, Gilder \& Haslam, 2004). However, it is unclear whether there are similarities and differences in nurse supervision between public and private sector hospitals and between Australia and the UK.

\section{Role Ambiguity in relation to patient}

A role is explained as what an employee perceives is the expected pattern of behaviours adopted at work while undertaking job tasks. Role ambiguity occurs when employees are unclear about what behaviours are expected (Katz \& Kahn, 1978). Katz \& Kahn (1978) argue that the expected behaviours are communicated to employees during social interactions with 
supervisors and colleagues, consequently, if supervisor-subordinate relationship is less than ideal, the context is right for role ambiguity to emerge. Within the nursing context, role ambiguity describes a situation where nurses are unclear about what they should do for a particular patient because of conflicting messages given by different authorities, such as a supervisor, senior manager and/or a senior clinical nurse. When nurses experience role ambiguity in relation to the patient, it means that they are unclear about what behaviours are expected of them in undertaking their work tasks. Such conditions are favourable for producing adverse outcomes for patients (Dawson, West \& Yan, 2008; Firth-Cozens, 2001). In contrast, role clarity (the opposite of role ambiguity) is enhanced by clear messages about expected workplace behaviours from supervisors, effective teamwork, improving competence plus the appropriate transfer of relevant knowledge and resources required to solve workplace problems (Jolke \& Duhan, 2000; Mueller \& Lee, 2002).

It is argued that nurses operate increasingly in an environment of role ambiguity (Elbright, Urden, Patterson \& Chalko, 2004). For example, when patients present with complicated circumstances (such as a trauma patient who also has bipolar disorder), role ambiguity is more likely. This is when less experienced nurses require the support and advice of the supervisor, senior clinical nurse and/or experienced team members. Nurse supervisors and/or experienced clinical nurses becomes invaluable in assisting nurses with vital information needed to make evidence-based, best practice clinical nursing decisions (Jolke \& Duhan, 2000; Rhoads, et al., 1994).

However, there may be differences across the public and private sector context. One explanation given for the differences is the implementation of management reforms within the public sector towards a more client-centred approach. In theory, management practices in the public sector were expected to improve, to deliver quicker decision-making and more flexible responses to meet different clients' demands. However, these claims are disputed by 
Kelly (2005), who argues that these reforms have led to more bureaucracy aimed at achieving efficiency and accountability goals. Consequently, the goal of becoming more client-centred is at best a secondary focus (Behn, 2002; Kelly, 2005; Lynn, 2001). This is evident in the lack of performance indicators measuring client satisfaction levels in many cases (Kelly, 2005). Consequently, some researchers believe that the requirement for public sector employees to understand more than the technical needs and requirements of the client outside the professional realm is also less of a priority.

\section{Discretionary Power}

Discretionary power refers to the degree to which employees have power in the workplace, especially in relation to decision-making (Ang, 2002). There is limited focus on discretionary power in the healthcare sector generally and the issue of discretionary power is not actively discussed, promoted or encouraged in Australia (Gollan, 2005). However, past research has established a significant relationship between role ambiguity and employees’ perceptions of discretionary power and job performance (Kalbers \& Cenker, 2008). This is an important issue for nurses because it has the potential to affect patient outcomes (Rafferty et al., 2007) as well as nurse outcomes (Laschinger, et al., 2004) because it is a vital ingredients for employees operating within the context of staff shortages as nurses do (Scotti, et al., 2007).

Within the public sector literature, discretionary power is a fundamental characteristic of Street Level Bureaucrats (SLBs). However, governments perceive SLBs' power as a problem because they remain unaccountable to the electorate and therefore it is argued that they would only service clients with easy or routine problems (Bohte \& Meier, 2000) or they could act corruptly and/or can discriminate based on race or gender or the co-cooperativeness of potential clients (Kaufman, 2001). However, Carrington (2005) argues that SLBs have this 
power because laws cannot anticipate all potential problems and consequences. Similarly, Lipsky (1980) and Winter (1990, p. 31) argue that the actions of SLBs are not arbitrary, instead SLBs 'give priority to easy, programmed routine cases at the expense of more complicated, nonprogrammed, and time-consuming cases' and 'limit information' or make 'access difficult' as a rationing technique to those patients who might require more resources than exist. This suggests that SLBs make rationing decisions for governments that inadequately resource new programs. In contrast, Nielsen (2006) in his study of Danish SLBs, argues that they engage in limiting supply to some clients so as to enhance their level of job satisfaction. As stated previously, Carroll and Steane (2002) argue that the implementation of recent reforms have affected Australian SLBs by increasing managerial control (and consequently, decreasing their discretionary power) whereas UK SLBs have been more affected by reforms separating policy development from service provision (Adcroft \& Willis, 2005). This suggests that discretionary power varies across countries.

A review of the literature suggests three types of discretionary power: 'rule', 'value' and 'task' discretion (Adler \& Asquith, 1993). Rule discretion refers to the extent to which SLBs are constricted by organisational or legal or fiscal rules. For example, there are laws that stop nurses from abusing patients. However, the argument is that the fewer the rules or the more vague the rules, the greater the power of SLBs. Numerous authors have identified the impact of task discretion associated with being a professional (and the specific knowledge associated with it) and how this has led to conflict when professionals are forced to be managers and respond to increased rule discretion often over-riding professional goals (Bolton, 2003; 2005; Ferlie, Ashburner, Fitzgerald \& Pettigrew, 1996). For example, Bolton (2003, p. 126) argues that nurse managers are expected to create empowering social environments, however, their primary performance indicators relate to operating effectively within 'tight budgetary controls and performance measures and targets'. Value discretion 
refers to the discretion given to those with knowledge and skills usually associated with professionals. The argument is that professionals have to have discretion because of the specialist knowledge required to make decisions in servicing the public. The outcome is that the more complex the task (such as brain surgery), and the more ambiguous the work environment, the greater the discretionary power (Hupe \& Hill, 2007).

From the management literature, discretionary power is conceptualised within the empowerment literature. Spreitzer (2007) identifies two conceptualisations of empowerment: structural (whether the organisational structures and processes facilitate optimal employee performance) and psychological empowerment (employees' responses and outcomes from working within a particular organisational empowerment context). Kanter’s (1993) theory of structural empowerment argues that organisations determine the quality of structural empowerment experienced by employees by influencing their access to resources, information, guidance and support. This then determines how much power an employee has in the workplace. Hence, Seibert, Silver and Randolph (2004) argue that the quality of structural empowerment is evident in employees' perceptions of psychological empowerment. Psychological empowerment has been conceptualised as: 'meaning' (which refers to a work goal moderated against an employee's own beliefs and values), 'competence' (self-efficacy about an employee's capabilities to undertake tasks), 'self-determination' (an employee's sense of discretionary power or autonomy about workplace choices) and 'impact' (an employee's beliefs about their impact in the workplace) (Spreitzer, 1995; 1996).

In summary, nurses would be expected to have value discretion because of their knowledge; however, it is expected that the implementation of reforms would have affected the task discretion of public sector employees (Ackroyd et al., 2007). However, reduced task discretion maybe more evident in Australian nurses (Carroll \& Steane, 2002) because their work tasks now include more record-keeping and data-collection (Brunetto et al., 2010). 
Further, nurses' perceptions of discretionary power across the public and private healthcare systems in Australia and UK are expected to be significantly related to supervision, teamwork and role ambiguity. The hypothesis to test this proposition is:

H1: There is a positive relationship between nurses' satisfaction with supervisorsubordinate relationships and teamwork, an inverse relationship with perceptions of role ambiguity and a positive relationship with discretionary power.

\section{Nurses in UK and Australia}

In Australia, 60\% percent of hospital beds are provided by the public sector and $40 \%$ are provided by the private and non-profit sectors (Gee, 2007). Additionally, because of publicprivate sector partnerships, public patients are treated in the private sector and vice versa. Further, the clinical work undertaken and the patient mix are similar across the public and private system in Australia (Brown \& Barnett, 2004). In contrast, the UK system via the National Health System (NHS) delivers healthcare to 92\% of all UK citizens (Ham, 2004). Additionally, the UK private system tends to focus on specialist services although its role is expanding slowly with the NHS contracting out some services to the private system.

However, Australia and UK have similar structures within, and approaches to, healthcare (Degeling Hill, Kennedy \& Maxwell, 2000) and consequently, nurses’ move from Australia to work in the UK and vice versa with ease (Buchan \& Seccombe, 2006). This is because both nations have systems of formal registration for nursing, have implemented systems of levels within registered nursing positions and have an increasing emphasis on the professionalization of nurses (Francis \& Humphreys, 1999), as well as a change in focus on training (Cunich \& Whelan, 2010). Additionally, nursing management across the UK and Australia similarly share difficulties with recruitment (Frijters, Shields \& Wheatley-Price, 2006) and retention (Cunich \& Whelan, 2010). Further, nurses in both nations are likely to 
have been affected by the implementation of reforms aimed at increased efficiency and costcutting (Adcroft \& Willis, 2005).

In contrast, the main difference is that Australian nurses are likely to have been more affected in terms of the supervisor-nurse relationship because of the implementation of reforms (Carroll \& Steane, 2002). It is therefore expected that, when compared with Australian nurses, UK nurses will be more satisfied with supervisor-subordinate relationships, which may affect their satisfaction with teamwork, perceptions of role ambiguity and empowerment. The following hypothesis is therefore proposed:

H2: Nurses in UK have higher levels of satisfaction with their supervisor-subordinate relationships and teamwork, lower perceptions of role ambiguity and higher perceptions of discretionary power, than nurses in Australia.

\section{Public and Private Sector nurses}

The UK and Australian public healthcare system are similar in that they both face an extra difficulty in retaining nurses, as evident in the number of nurses moving from the public to private sector (Doiron, Hall \& Jones, 2008). In Australia, both public and private sector hospitals have similar acute clinical settings and experience comparable patient case mix, because of public-private partnerships and contracting out of beds (Brown \& Barnett, 2004). In the UK, private hospitals have traditionally provided specialist services; however, this situation is changing as some NHS work is contracted out to private hospitals (Ham, 2004). It is expected that the biggest difference between public and private sector nurses will be in management practices because Steane (1997) argues that the values informing management practices in the public sector may be different to the private sector. Additionally, Currie and Procter (2002) argue that public sector managers have more managerial power compared with their private sector counterparts and Hoque, et al. (2004) challenge whether the changes have delivered a more effective form of supervision in the public sector. They argue that 
public sector managers have been ill-equipped in terms of resourcing or management upskilling to motivate their subordinates to deliver greater effectiveness. Further, Hardie and Critchley (2008) suggest that the Australian public perceive that private sector hospitals deliver a higher quality of care, suggesting a better managed context. To examine this premise, the following hypothesis is proposed:

H3: Private sector nurses have higher levels of satisfaction with their supervisorsubordinate relationships and teamwork, lower perceptions of patient role ambiguity and in turn, higher perceptions of discretionary power, than public sector nurses.

\section{METHODS}

This research uses a cross-sectional design to gather data to test the relationship between nurses' satisfaction with supervisor-subordinate relationships and teamwork, plus their perceptions of role ambiguity and discretionary power. Data were collected using a surveybased, self-report strategy (Ghauri \& Gronhaug 2002) during 2008 - 2010. The emerging patterns of data were then compared with the findings of previous research.

All nurses in the study are from hospitals that have similar acute clinical settings and who experience comparable patient case mixes. The Australian sample included nurses from four Australian states (New South Wales, Queensland, Western Australia and Victoria), working in either public or private sector small ( $<300$ beds), medium (300-500 beds) or large (>500 beds) hospitals. The 2 public hospitals comprised 1 large and 1 medium hospital and the 6 private hospitals comprised 1 large, 2 medium and 3 small hospitals. The public sector UK sample comprised nurses working in two National Health Scheme (NHS) Foundation Trusts in the north of England, covering 3 large public sector hospitals. The private sector UK nurse sample came from 15 small hospitals across England and Scotland. 
To gather data from Australian nurses, 4,800 anonymous surveys were distributed to the 8 hospitals and nurses were invited to participate. The response was 1064 useable surveys - an overall response rate of approximately 22\%. To gather data from the England, 3,500 anonymous surveys were distributed to the 3 public and 15 small hospitals and all nurses were invited to complete them. In total, 725 responses were received from this sample - a response rate of approximately $21 \%$.

\section{Measures}

The measures were taken from the extant literature and presented using statements to be rated on a 6-point Likert-type scale, with $1=$ strongly disagree, ranging to $6=$ strongly agree. Table 1 details the items used in the survey. Satisfaction with the quality of the supervisornurse relationship was measured using a seven-item uni-dimensional scale (LMX-7), developed by Graen and Uhl-Bien (1995). According to Gerstner and Day (1997), the unidimensional scale updated by Graen and Uhl-Bien (1995) is the most commonly used tool for measuring LMX quality and has the best psychometric properties of all they instruments reviewed. Nurses' satisfaction with Teamwork was measured using Rubin, Palmgreen and Sypher's (1994) 5-item version of an organisational culture survey developed by Glaser, et al. (1987), using employees' level of satisfaction as a function of teamwork, morale, information flow, involvement and supervision. Role Ambiguity in relation to the patient was measured using 3 items of Johlke and Duhan's (2000) instrument and was reverse scored. This means that a higher score reflects role clarity, whereas a lower score represents role ambiguity. Nurses' perception of discretionary power - the dependent variable - was operationalised using Spreitzer's (1996) 3-item measure of self-determination. All tools used in this study were from previously validated test banks, and the reliability was tested via

Cronbach's alpha scores (see Table 3). All scores were above the minimum requirement of 
0.7. Two other characteristics were measured: first, whether respondents worked in private or public sector hospitals, and second, whether in hospitals located in Australia or England.

\section{Data analysis}

Survey data were analysed using PASW 18. Correlations and regression analyses were undertaken to test nurses' satisfaction with supervisor-nurse relationships and teamwork, and their perceptions of role ambiguity and discretionary power. Path analysis was used to test the 'goodness of fit' of the proposed model and to test the relationship between nurses' satisfaction with supervisor-subordinate relationships and teamwork, perceptions of role ambiguity and discretionary power. In particular, path analysis using an ordinary least squares (OLS) approach was used to test the hypothesis. The sequence begins by using a deductive approach to determine the variables and their order within the path (Bento \& Bento, 2004). This is followed by using SPSS to undertake a number of multiple regressions to produce a standardized regression coefficient (beta) which shows the direct effect of an independent variable on a dependent variable in the path model. The partial correlations are presented in the path (Schumacker \& Lomax, 2004). The advantage of path analysis is that it permits more than one equation to predict the dependent variable (i.e. discretionary power) and therefore it includes the indirect impact of supervisor-subordinate relationships, teamwork and role ambiguity into the bigger equation. OLS is an explanation of variance and the overall $\mathrm{R}^{2}$ measure identifies the 'goodness of fit' overall for the proposed model (Ahn, 2002).

Additionally, a MANOVA was used twice to firstly examine the impact of working in a public or private hospital and secondly to examine the impact of being in a UK or Australian hospital upon four dependent variables (supervisor-nurse relationships, teamwork, role ambiguity and discretionary power). If the multivariate $\mathrm{F}$ value is significant, then it means 
that there is a significant difference in the means for supervisor-nurse relationships, teamwork, role ambiguity and discretionary power across the public-private sectors and/or Australian-UK hospitals.

\section{RESULTS}

The Australian private sector nursing sample comprised 868 females and 32 males, of which 486 were aged over 45 years of age, 341 were aged between 30 and 45 years of age and 74 were aged less than 30 years of age. The Australian public sector sample comprised 143 females and 21 males, of which 56 were aged over 45 years of age, 72 were aged between 30 and 45 years of age and 36 were aged less than 30 years of age.

The UK private sector sample comprised 263 females and 27 males, of which 171 were aged over 45 years of age, 96 were aged between 30 and 45 years of age and 23 were aged less than 30 years of age. The UK public sector sample comprised 415 females and 20 males, of which 166 were aged over 45 years of age, 177 were aged between 30 and 45 years of age and 92 were aged less than 30 years of age.

In terms of job status, the sample included: (a) Supervisors (55 from the Australian private sample, 3 from the Australian public sample, 28 from the UK private sample and 66 from the UK public sample); (b) Registered Nurses (RNs) (629 from the Australian private sample, 136 from the Australian public sample, 169 from the UK private sample and 338 from the UK public sample); (c) Enrolled Nurses (ENs) (103 from the Australian private sample, 18 from the Australian public sample, 10 from the UK private sample and 2 from the UK public sample); (d) Nurse Assistants (4 from the Australian private sample, 7 from the Australian public sample, 5 from the UK private sample and 4 from the UK public sample); and (e) several nurses (211 of them overall) did not provide this information. 


\section{Factor Analysis}

Each variable has been developed and validated in previous research. Hence the findings detailed here are the results of a confirmatory factor analysis. The correlation matrix identified many correlations exceeding .3, indicating the matrix was suitable for factoring. The Bartlett's test for Sphericity was significant (Chi-square value=19,696.490, $\mathrm{p}<.001$. df 171) and the Kaiser-Meyer-Olkin (KMO) measure of sampling adequacy was .872 - well above the .7 requirement. When Principal Axis Factoring was undertaken to extract the variables, four factors had eigenvalues greater than one and $74.106 \%$ of the variance could be explained using these four factors -ensuring the validity of the variables (See Table 1).

[Insert Table 1 here]

\section{Results from analysis}

Table 2 identifies statistically significant correlation coefficients between SupervisorSubordinate Relationships, Teamwork, Role Ambiguity and Discretionary Power as well as for the 'public-private' and 'Australian-UK' variables and the demographic variablesgender, age and job status (position) in the organisation. Hence, it was important to test not only the impact of the stated variables, but also the demographics across the 'public private' and 'Australian-UK' context.

[Insert Table 2 here]

In response to the first hypothesis (H1: There is a positive relationship between nurses' satisfaction with supervisor-subordinate relationships and teamwork, an inverse relationship with perceptions of role ambiguity and a positive relationship with discretionary power), a hierarchical regression analysis was used (See Table 3 for beta scores). In summary, the findings for Australian nurses are that demographic factors accounted for $1.6 \%$ of the 
variance of discretionary power of nurses and the variables - Supervisor-Subordinate Relationships, Teamwork and Role Ambiguity - accounted for $11.2 \%$ of the variance of discretionary power of nurses $\left(R^{2}=.112\right)$. For UK nurses, demographic factors accounted for $2.2 \%$ of the variance of discretionary power of nurses and the variables - SupervisorSubordinate Relationships, Teamwork and Role Ambiguity - accounted for $25.3 \%$ of the variance of discretionary power of nurses $\left(R^{2}=.253\right)$. For public sector nurses, demographic factors accounted for .6\% of the variance of discretionary power of nurses and the variables Supervisor-Subordinate Relationships, Teamwork and Role Ambiguity - accounted for $17.7 \%$ of the variance of discretionary power of nurses $\left(R^{2}=.177\right)$. For Australian nurses, demographic factors accounted for $1.1 \%$ of the variance of discretionary power of nurses and the variables - Supervisor-Subordinate Relationships, Teamwork and Role Ambiguity accounted for $13.3 \%$ of the variance of discretionary power of nurses $\left(R^{2}=.133\right)$ (See Table 3 and figure 1).

In each case, there was a somewhat direct relationship between supervisorsubordinate relationships and an inverse relationship with role ambiguity. Hypothesis 1 is therefore supported.

\section{[Insert Table 3 here]}

To address the second hypothesis (H2: Nurses in UK have higher levels of satisfaction with their supervisor-subordinate relationships and teamwork, lower perceptions of role ambiguity and higher perceptions of discretionary power, than nurses in Australia), a MANOVA was undertaken. The findings evident in Table 4 indicate that there are significant differences across the UK and Australian nursing cohort in the means for nurses' satisfaction with supervisor-subordinate relationships and teamwork only, and the means for Australian nurses were higher than for UK nurses; hence hypothesis 2 is rejected. 
[Insert Table 4 here]

To address the third hypothesis (H3: Private sector nurses have higher levels of satisfaction with their supervisor-subordinate relationships and teamwork, lower perceptions of patient role ambiguity and in turn, higher perceptions of discretionary power, than public sector nurses), a second MANOVA was undertaken. The findings evident in Table 5 indicate that there are significant differences across the public and private nursing cohorts in the means for nurses' satisfaction with supervisor-subordinate relationships and teamwork, as well as for nurses' perceptions of role ambiguity and discretionary power. The means for private sector nurses are higher compared with those for the public sector - hence hypothesis 3 is supported.

[Insert Table 5 here]

From the path analysis (see Figure 1), more than a quarter of UK nurses' and eleven percent of Australian nurses’ variance of discretionary power can be accounted for by supervisorsubordinate relationships, teamwork and role ambiguity. Additionally almost a fifth of public sector nurses' and thirteen percent of private sector nurses' variance of discretionary power can be accounted for by supervisor-subordinate relationships, teamwork and role ambiguity.

[Insert Figure 1 here]

\section{DISCUSSION}

\section{Study Limitations}

There were some limitations to this study which need to be considered before discussing the results. First, the Australian sample was on average older than the UK sample. Second, common method bias is a possibility within self-report cross-sectional studies (Podsakoff, MacKenzie, Lee \& Podsakoff, 2003), where common method variance may influence the significance of relationships between variables. While factor analysis was used to reduce bias, there was no aprioi marker variable. Even so, Richardson, Simmering and 
Sturman (2009, p. 794) would argue that overall, using the CFA marker technique for detecting bias is not recommend 'because of its generally low accuracy at detecting the presence or absence of bias, on average across all conditions.'

However, Spector (1994) argues that self reporting methods is legitimate for gathering data about employees’ perceptions, as long the instrument reflects an extensive literature review and pattern-matching is used to support interpretations of the data. Third, this study was limited to two nations and therefore cannot be generalised beyond those nations.

\section{Discussion of results}

The aims of this study were to compare the similarities and differences in the links between nurses' satisfaction with supervisor-nurse relationships, teamwork, perceptions of their role ambiguity in relation to their patients plus perceptions of their discretionary power, and to compare public and private sector nurses and those in Australian and UK hospitals. Previous research had already demonstrated the significance of the relationship between quality supervisor-nurse relationships and teamwork (Edmondson, 2003; Ellemers, et al., 2004), and discretionary power (Ackroyd et al., 2007; Hoyle \& John, 1995) and an inverse relationship with role ambiguity (Mueller \& Lee, 2002). However, few studies had compared the impact of these factors for public and private nurses, or within Australia compared with the UK. Our results therefore make a contribution to both theoretical and empirical knowledge.

The path analysis figure shows a significant association between nurses' satisfaction with supervisor-nurse relationships, teamwork, perceptions of role ambiguity and discretionary power for each cohort. While the impact upon the public-private and AustraliaUK samples differed, with the UK nurses being most affected, supervisor-subordinate relationships, teamwork and role ambiguity are important workplace factors impacting upon nurses’ perceptions of discretionary power. 
This is an important finding because past research suggests that discretionary power is vital for those occupations identified as suffering from staff shortages (Scotti et al., 2007) as is the case for nurses in Australia and the UK. It is argued that nurse shortages are a longterm problem because a majority of present day nurses will retire within the next 15 years (OECD, 2006). Hence, it will become increasingly important to ensure that nurses have the level of discretionary power required to maximise their effectiveness in the workplace. In theory, nurses are categorised as skilled professionals and consequently would be expected to have high levels of task discretion because of their knowledge and experience (Adler \& Asquith, 1993). However, the impact of the increase in rule discretion, resulting from the increase in managerial control given to Australian supervisors, may be one reason explaining why the public sector nurses have the lowest perceptions of discretionary power amongst all of the cohorts (and significantly lower than private sector nurses).

These findings may provide further evidence for the work of Hoque et al. (2004) who argued that public sector supervisors have more power than private sector supervisors, however, they appeared not to have the skills required to provide effective supervision. LMX theory argues that effective supervisor-subordinate relationships are based on established social interactions that empower employees to achieve productive outcomes by providing access to information, resources and support as required (Mueller \& Lee, 2002). Such an environment would be characterised by high levels of satisfaction with supervisorsubordinate relationships and teamwork, low levels of role ambiguity and high levels of discretionary power. The closest workplace to such a work environment is evident in the private sector (comprising both Australian and UK nurses), however, even the nurses in that sector reported that there is potential for improvement. Such findings provide support for Hardie et al. (2008) and Mrayyan (2005) who argued that the private health system manages its employees better than the public healthcare system do. 
Our study took place against a background of management reforms in Australia pushing for greater efficiencies, leading to an expectation that nurses in UK hospitals would therefore experience higher levels of satisfaction with their supervisor-subordinate relationships than those in Australian hospitals. In contrast, the results imply that Australian nurses were significantly more satisfied with supervisor-nurse relationships than UK nurses. However, the UK nurses were significantly more satisfied with teamwork compared with the Australian nurses. Further, there is potential for improvement with supervisor-nurse relationships and teamwork in both cohorts. It may be time to challenge existing healthcare management paradigms that choose strong managerial control associated with low empowerment in healthcare management generally (Gollan, 2005) in favour of more empowering relationships that are more applicable for retaining professionals (Drucker, 2005).

\section{CONCLUSION}

Within the global context of nurse shortages, high nurse turnover and looming retirements of older nurses, there were a number of findings from this study. New knowledge is consequently now available about the similarities and differences in the links between the supervisor-subordinate relationships, teamwork, role ambiguity and discretionary power of nurses across public and private sector hospitals and between Australia and the UK. These results add to both theoretical and empirical knowledge. The biggest difference for nurses is between public and private sector hospital workplaces, with public sector nurses being significantly less satisfied with the relationships with their supervisors and the teamwork, and experiencing significantly higher levels of role ambiguity and significantly lower perceptions of discretionary power than their private sector counterparts. Such workplace conditions compromise nurses' productivity in particular and organisational effectiveness overall. 
Interestingly, the differences in the work context across UK and Australian hospitals are far less than between the public and private sectors, and in terms of discretionary power and role ambiguity, the workplaces are similar in the two nations. However, because of the global reach and importance of nursing, further research would be of value in other countries, enabling broader comparisons.

The findings challenge Australian and UK healthcare managers, particularly in the public sector to consider improvements to supervision practices - away from strong managerial control and towards empowering effective supervisor-subordinate relationships. There is an increasing focus on delivering evidence-based best-practice healthcare to patients; however, these findings suggest less than ideal opportunities are available for nurses to access information, resources and support when needed. Much of the needed improvement requires a changing role for the nurse supervisor - professionalising the nurse supervisor's role by moving it away from being an organisational supervisor and towards being a professional mentor and role-model. Hence, the success of plans for professionalizing nursing may well depend on changed roles for nurse supervisors. 


\section{REFERENCES}

Ackroyd, S., Kirkpatrick, I., \& Walker, R. (2007). Public management reform in the UK and its consequences for professional organization: A comparative analysis. Public Administration, 85(1), 9-26.

Adcroft, A., \& Willis, R. (2005). The (un)intended outcome of public sector performance measurement. The International Journal of Public Sector Management, 18(4/5), 386400.

Adler, M., \& Asquith, S. (1993). Discretion and power. In M. Hill (Ed.), The Policy Process: A Reader (pp. 399-406). Hemel Hempstead: Harvester.

Ahn, J. (2002). Beyond single equation regression analysis: Path analysis and multi-stage regression analysis. American Journal of Pharmaceutical Education, 66, 37-42.

Behn, R. (2002). The psychological barriers to performance management or why isn't everyone jumping on the performance management bandwagon? Public Performance and Management Review, 26(1), 5-25.

Bento, A, \& Bento, R. (2004). The use of causal analysis techniques in Information Systems research: A methodological note. Journal of Information Technology Management, 15(3), 44-51.

Bindi, K., Clegg, C., Patterson, M., Robertson, A., Stride, C., Wall, T., Woods, S. (2008). The impact of human resource management practices on company productivity: A longitudinal study. Personnel Psychology, 61, 467-501.

Bolton, S. (2003). Multiple roles? Nurses as managers in the NHS. International Journal of Public Sector Management, 16(2), 122-130.

Bolton, S. (2005). Making up Managers: the case of NHS Nurses Work. Employment and Society, 19(1), 5-24.

Bond, M. (2002). Reclaiming the Individual from Ecological Analysis- A 20-Year Odyssey: Comment on Oyserman et al. (2002). Psychological Bulletin, 128(1), 73-77.

Brown, L., \& Barnett, J. (2004). Is the corporate transformation of hospitals creating a new hybrid healthcare space? Social Science Medicine, 58(427-44).

Brunetto, Y., \& Farr-Wharton, R. (2006). A comparison of the administrative subculture of Australian public and private sector employees. International Journal of Public Administration, 29(8), 619-638.

Brunetto, Y., \& Farr-Wharton, R. (2007). Comparing the impact of management practices on public sector nurses' and administrative employees' commitment to the organisation. Asian Pacific Journal of Health Management, 2(1), 17-34. 
Brunetto, Y., Farr-Wharton, R., \& Shacklock, K. H. (2010). The impact of supervisorsubordinate relationships on morale: Implications for public and private sector nurses' commitment. Human Resource Management Journal, 20(2), 206-225.

Brunetto, Y., Farr-Wharton, R., \& Shacklock, K. H. (2011 forthcoming). Using the Harvard HRM model to conceptualise the impact of changes to supervision upon HRM outcomes for different types of public sector employees. International Journal of Human Resource Management, 22(3).

Buchan, J., \& Seccombe, I. (2006). Worlds Apart? The UK and International Nurses. Edinburgh: Royal College of Nursing.

Carroll, P., \& Steane, P. (2002). Australia, the New Public Management and the new millenium. In K. McLauglin, S. Osborne \& E. Ferlie (Eds.), New Public Management: current trends and future prospects (pp. chapter 12). London: Routledge.

Cohen, J. (2006). The aging nursing workforce: How to retain experienced nurses Journal of Healthcare Management, 51(4), 233- 246.

Conger, J. A., \& Kanungo, R. A. (1988). Behavioral dimensions of charismatic leadership. In J. A. Conger \& R. N. Kanango (Eds.), Charismatic leadership: The elusive factor in organizational effectiveness (pp. 78-97). San Francisco, CA: Jossey-Bass.

Cunich, M., \& Whelan, S. (2010). Nurse education and the retention of registered nurses in New South Wales. The Economic Record, 86(297), 396-413.

Currie, G., \& Procter, S. (2002). The interaction of human resource policies and practices with the implementation of teamworking: Evidence from the UK public sector. The International Journal of Human Resource Management 14(4), 581-599.

Dawson, J., West, M., \& Yan, X. (2008). Positive and negative effects of team working in healthcare: 'Real' and 'pseudo' teams and their impact on healthcare safety. Working Paper, Aston University, Birmingham, UK.

Degeling, P., Hill, M., Kennedy, J., \& Maxwell, S. (2000). A cross-national study of differences in the identities of nursing in England and Australia and how this has affected nurses’ capacity to respond to hospital reform. Nursing Inquiry, 7, 120-135.

Doiron, D., Hall, J. P., \& Jones, G. (2008). Is there a crisis in nursing retention in New South Wales? Australia and New Zealand Health Policy, 5(19), 1-12.

Drach-Zahavy, A., \& Pud, D. (2010). Learning mechanisms to limit medication administration errors. Journal of Advanced Nursing, 66(4), 794-805. 
Edmondson, A. (1999). Psychological safety and learning behavior in work teams. Administrative Science Quarterly, 44, 350-383.

Elbright, P., Urden, L., Patterson, E., \& Chalko, B. (2004). Themes surrounding novice nurses' near-miss and adverse event situations. Journal of Nursing Administration, 34(11), 531-538.

Ellemers, N., Gilder, D. D., \& Haslam, A. S. (2004). Motivating individuals and groups as work: a social identity perspective on leadership and group performance. Academy of Management Review, 29(3), 459-478.

Ferlie, E., Pettigrew, A., Ashburner, L., \& Fitzgerald, L. (1996). The New Public Management in Action. Oxford: Oxford University Press.

Firth-Cozens, J. (2001). Teams, Culture and Managing Risk. In C. Vincent (Ed.), Clinical Risk Management: enhancing patient safety (2nd ed., pp. 355-368).

Frijters, P., Shields, M., \& Wheatley-Price, K. (2006). Investigating the quitting decision of Nurses: Panel data evidence from the British Health Service. Health Economics, 16, 57-73.

Gee, C. (2007). The Contribution of the Australian Private Sector Hospitals Sector. Asian Pacific Journal of Health Management, 2(1), 41-46.

Gerstner, C., \& Day, D. (1997). Meta-analytic review of leader-member exchange theory: Correlates and construct issues. Journal of Applied Psychology, 82, 827-844.

Ghauri, P., \& Grønhaug, K. (2002). Research methods in business studies: A practical guide (2nd ed.). Harlow, UK: Financial Times Prentice Hall.

Gollan, P. (2005). High Involvement management and human resource sustainability: The challenges and opportunities. Asia Pacific Journal of Human Resources, 43(1), 18-33.

Gomez, C., \& Rosen, B. (2001). The leader member exchange as a link between managerial trust and employee empowerment. Group and Organisational Management,, 26(1), 53-69.

Graen, G., \& Uhl-Bien, M. (1995). Relationship-based approach to leadership: Development of leader-member exchange (LMX) theory of theory over 25 years: Applying a multilevel multi-domain perspective. Leadership Quarterly, 6(2), 219-247.

Grapentine, T. (2000). Path analysis vs. structural equation modeling. Marketing Research,, 12(3), 13-20.

Ham, C. (2004). Health Policy in UK. London: McMillan.

Hofstede, G. (1980). Culture's consequences. Beverley Hills, CA: Sage Publications. 
Hoque, K., Davis, S., \& Humphries, M. (2004). Freedom to do what you are told: Senior management's autonomy in an NHS Acute Trust. Public Administration, 82(2), 355376.

Hoyle, E., \& John, P. (1995). Professional knowledge and professional practice. London: Cassell.

Johlke, M. C., \& Duhan, D. F. (2000). Supervisor communication practices and service employee job outcomes. Journal of Service Research, 3(2), 154-165.

Kalbers, L., \& Cenker, W. (2008). The Impact of Exercised Responsibility, Experience, Autonomy, and Role Ambiguity on Job Performance in Public Accounting. Journal of Managerial Issues, 20(3), 327-347.

Katz, D., \& Kahn, R. (1978) The social psychology of organizations. New York: Wiley. Katzenbach, J., \& Smith, D. (1993). The wisdom of teams: Creating the high-performing organisation. Boston: Harvard School Press.

Laschinger, H. K. S., Finegan, J., Shamian, J., \& Wilk, P. (2004). A longitudinal analysis of the impact of workplace empowerment on work satisfaction. Journal of Organizational Behavior, 25(4), 527.

Laschinger, H. K. S., Purdy, N., \& Almost, J. (2007). The impact of leader-member exchange quality, empowerment and core self-evaluation on nurse manager's job satisfaction. The Journal of Nursing Administration, 37(5), 221-229.

Maynard-Moody, S., \& Mushero, M. (2003). Cops, teachers, counselors: Stories from the front lines of public service. Michigan: University of Michigan Press.

Mrayyan, M. T. (2005). Nurse job satisfaction and retention: comparing public to private hospitals in Jordan. Journal of Nursing Management 13(1), 40-50.

Mueller, B., \& Lee, J. (2002). Leader-member exchange and organizational communication satisfaction in multiple contexts. Journal of Business Communication, 39(2), 220-244.

OECD. (2006). Live longer. Paris: Organisation for Economic Co-operation and Development.

Podsakoff, P. M., MacKenzie, S. B., Lee, C. A., \& Podsakoff, N. P. (2003). Common method biases in behavioral research: A critical review of the literature and recommended remedies. Journal of Applied Psychology, 88(5), 879-903.

Rafferty, A., Clarke, S., Coles, J., Ball, J., James, P., McKee, M., \& Aiken, L. (2007). Outcomes of variation in hospital nurse staffing in English hospitals: Cross-sectional analysis of survey data and discharge records. International Journal of Nursing Studies, 44, 175-182. 
Richardson, H.A., Simmering, M.J. and Sturman, M.C. (2009), “A tale of three perspectives: Examining post hoc statistical techniques for detection and correction of common method variance”, Organizational Research Methods, 12:762-800.

Rubin, R., Palmgreen, P., \& Sypher, H. (1994). Communication research measures: A sourcebook. New York: Guildford Press.

Schriesheim, C. A., Castro, S. L., \& Cogliser, C. C. (1999). Leader-member exchange (LMX) research: A comprehensive review of theory, measurement, and data-analytic practices. The Leadership Quarterly, 10(1), 63-113.

Schumacker, R.E., \& Lomax, R.G. (2004). A beginner's guide to structural equation modeling (2nd ed.). New Jersey: IEA

Scotti, D. J., Harmon, J., \& Behson, S. J. (2007). Links among high-performance work environment, service quality and customer satisfaction: An extension to the healthcare sector. Journal of Healthcare Management, 52(2), 109-125.

Secombe, I., \& Smith, G. (1997). Taking part: Registered nurses and the labour market in 1997. Grantham, England: Grantham Book Services.

Seibert, S., Silver, S., \& Randolph, W. (2004). Taking empowerment to the next level: A multiple-level model of empowerment, performance, and satisfaction. Academy of Management Journal, 47, 332-349.

Sparrowe, R., \& Linden, R. (1997). Process and structure in leader-member exchange. Academy of Management Journal, 22(2), 522-552.

Spector, P. E. (1994). Using self-reported questionnaires in OB research: A comment on the use of a controversial method. Journal of Organisational Behavior, 15(5), 385-392.

Spreitzer, G. (1995). Psychological empowerment in the workplace: Dimensions, Measurement and Validation. Academy of Management Journal, 38(5), 1442-1465.

Spreitzer, G. (1996). Social Structural Characteristics of Psychological Empowerment. Academy of Management Journal, 39(2), 483-504.

Spreitzer, G. (2007). Taking stock: A review of more than twenty years of research on empowerment at work. In C. Cooper \& J. Barling (Eds.), The handbook of organizational behaviour. Thousand Oaks, CA.: Sage Publications.

Spreitzer, G., Kizilos, M. A., \& Nason, S. W. (1997). A dimensional analysis of the relationship between psychological empowerment and effectiveness, satisfaction, and strain. Journal of Management, 23(5), 679-704.

Steane, P. (1997). Oils Ain’t Oils! Strategy Across Sectors. International Journal of Public Sector Management, 10, 461-470. 
Tauton, R. L., Boyle, D. K., Woods, C. Q., Hansen, H. E., \& Bott, M. J. (1997). Manager leadership and retention of hospital staff nurses. Western Journal of Nursing Research, 19(2), 205-226.

Thomas, E., Sexton, B., \& Helmrich, R. (2003). Discrepant attitudes about teamwork among critical care nurses and physicians. Critical Care Medicine, 31(3), 956-959.

Thompson, C. A., \& Prottas, D. J. (2006). Relationships among organisational family support, job autonomy, perceived control, and employee well being. Journal of Occupational Health Psychology, 11(1), 100-118.

Vincent, C. (2006). Patient safety London: Churchill Livingstone.

Wain, K. (1993). Lifelong learning education: Illiberal or repressive? Educational Philosophy and Theory, 25(1), 58-78.

Wayne, S., Shore, L., \& Linden, R. (1997). Perceived organisational support and leader exchange: A social exchange perspective. Academy of Management Journal, 40(1), 82-111.

Yrie, A., Hartman, S., \& Galle, W. (2003). Examining communication style and leadermember exchange: considerations and concerns for managers. International Journal of Management 20(1), 92-100.

Yukl, G. (2006). Leadership in organizations (6th ed.). Upper Saddle River, NJ: PearsonPrentice Hall. 
TABLES

Table 1: Factor Analysis using Principal Axis Factoring as the extraction method and Varimax with Kaiser Normalization as the Rotation method (used to classify variables)

\begin{tabular}{|c|c|c|c|c|}
\hline Variable & $\begin{array}{c}\text { Factor } \\
1\end{array}$ & $\begin{array}{l}\text { Factor } \\
2\end{array}$ & $\begin{array}{c}\text { Factor } \\
3\end{array}$ & $\begin{array}{c}\text { Factor } \\
4\end{array}$ \\
\hline \multicolumn{5}{|l|}{ Supervisor-Subordinate Relationship } \\
\hline My supervisor is satisfied with my work & .699 & & & \\
\hline $\begin{array}{l}\text { My supervisor understands my work } \\
\text { problems and needs }\end{array}$ & .808 & & & \\
\hline $\begin{array}{l}\text { My supervisor knows how good I am at my } \\
\text { job }\end{array}$ & .803 & & & \\
\hline $\begin{array}{l}\text { My supervisor is willing to use her/his } \\
\text { power to help me solve work problems }\end{array}$ & .814 & & & \\
\hline $\begin{array}{l}\text { I have a good working relationship with my } \\
\text { supervisor }\end{array}$ & .675 & & & \\
\hline $\begin{array}{l}\text { My supervisor is willing to help me at work } \\
\text { when I really need it }\end{array}$ & .83 & & & \\
\hline \multicolumn{5}{|l|}{ Teamwork } \\
\hline $\begin{array}{l}\text { People I work with resolve disagreements } \\
\text { cooperatively }\end{array}$ & & .716 & & \\
\hline $\begin{array}{l}\text { People I work with are cooperative and } \\
\text { considerate }\end{array}$ & & .84 & & \\
\hline $\begin{array}{l}\text { People I work with constructively confront } \\
\text { problems }\end{array}$ & & .776 & & \\
\hline $\begin{array}{l}\text { People I work with are concerned about } \\
\text { each other }\end{array}$ & & .711 & & \\
\hline \multicolumn{5}{|l|}{ Role Ambiguity } \\
\hline $\begin{array}{l}\text { I am certain which specific nursing } \\
\text { strengths I should present to my patients. }\end{array}$ & & & .772 & \\
\hline $\begin{array}{l}\text { In my job, I am certain how much service I } \\
\text { should provide to my patients }\end{array}$ & & & .921 & \\
\hline $\begin{array}{l}\text { I am certain of what I am expected to do for } \\
\text { my patients }\end{array}$ & & & .77 & \\
\hline \multicolumn{5}{|l|}{ Discretionary Power } \\
\hline $\begin{array}{l}\text { I can decide on my own how to go about } \\
\text { doing my work }\end{array}$ & & & & .624 \\
\hline $\begin{array}{l}\text { I have opportunities for independence and } \\
\text { freedom in how I do my job }\end{array}$ & & & & .927 \\
\hline $\begin{array}{l}\text { My impact on what happens in my ward is } \\
\text { large }\end{array}$ & & & & .624 \\
\hline
\end{tabular}


Table 2: Correlations and Cronbach's alpha coefficients

\begin{tabular}{|c|c|c|c|c|c|c|c|c|c|}
\hline & & 1 & 2 & 3 & 4 & 5 & 6 & 7 & 8 \\
\hline 1 & Gender & 1 & & & & & & & \\
\hline 2 & Age & .04 & 1 & & & & & & \\
\hline 3 & Job Status & -.47 & .02 & 1 & & & & & \\
\hline 4 & LMX & .04 & $.05^{*}$ & $.06^{*}$ & 1 & $(.93)$ & & & \\
\hline 5 & Teamwork & $.07 * *$ & $.08^{*}$ & .01 & $.4^{* *}$ & 1 & (.84) & & \\
\hline 6 & Role Amb & $.09 * *$ & $.11^{* *}$ & .01 & $.22 * *$ & $.16^{* *}$ & $1(.9)$ & & \\
\hline 7 & Discr.Power & .04 & $.12 * *$ & .02 & $.35 * *$ & $.33 * *$ & $.17 * *$ & 1 & (.895) \\
\hline 8 & Aust-UK & -.03 & $-.07 *$ & -.01 & $-.08 * *$ & $.06 *$ & .02 & .02 & 1 \\
\hline 9 & Private-public & -.03 & $-.21 * *$ & $-.2^{* *}$ & $-.19 * *$ & $-1 * *$ & $-.2 * *$ & $-.17 * *$ & $.46 * * 1$ \\
\hline
\end{tabular}

Table 3: Hierarchical Regression analysis: Predictors of Nurses' perception of Discretionary Power for Australian, UK, Public sector and Private sector samples

\begin{tabular}{|c|c|c|c|c|c|c|c|c|}
\hline \multirow[t]{2}{*}{ Variables } & \multicolumn{2}{|c|}{ Aust } & \multicolumn{2}{|c|}{ UK } & \multicolumn{2}{|c|}{ Public sector } & \multicolumn{2}{|c|}{ Private sector } \\
\hline & Model 1 & Model 2 & Model 1 & Model 2 & Model 1 & Model 2 & Model 1 & Model2 \\
\hline Gender & $.068 *$ & .038 & .004 & -.03 & .054 & .001 & .016 & .001 \\
\hline Age & $.105^{* *}$ & $.066 *$ & $.133 * *$ & $.108 * *$ & .049 & .05 & $.101^{* *}$ & $.076 *$ \\
\hline $\begin{array}{l}\text { Job status } \\
\text { LMX }\end{array}$ & -.022 & $\begin{array}{l}-.02 \\
.178^{* *}\end{array}$ & .06 & $\begin{array}{l}.014 \\
.344^{* *}\end{array}$ & -.011 & $\begin{array}{l}-.003 \\
.281 * *\end{array}$ & -.012 & $\begin{array}{l}-.016 \\
.203^{* *}\end{array}$ \\
\hline Teamwork & & $.205^{* *}$ & & $.208 * *$ & & $.22 * *$ & & $207^{* *}$ \\
\hline $\begin{array}{l}\text { Role } \\
\text { Ambiguity }\end{array}$ & & .05 & & .093 & & .057 & & $.062 *$ \\
\hline $\mathrm{F}$ & $5.923^{* *}$ & $25.809 * *$ & $5.487^{* *}$ & $\begin{array}{l}45.169 * \\
*\end{array}$ & 1.128 & $\begin{array}{l}22.047 * \\
*\end{array}$ & $4.269 *$ & $33.069 * *$ \\
\hline $\mathbf{R}^{2}$ & .016 & .128 & .022 & .275 & .006 & .183 & .011 & .144 \\
\hline
\end{tabular}

Table 4: Results from MANOVA: Testing for differences in Means for Nurses in Australia and the UK

\begin{tabular}{lccccc}
\hline & \multicolumn{2}{c}{ Australia $^{\#}$} & \multicolumn{2}{c}{ UK $^{\# \#}$} & \\
& Mean $^{\mathbf{a}}$ & SD & Mean & SD & F score \\
\hline Supervisor-Subordinate Rel/ship & 4.69 & 1.08 & 4.53 & 1.03 & $10.393^{* *}$ \\
Teamwork & 4.57 & .81 & 4.67 & .76 & $5.9^{* *}$ \\
Role Ambiguity & 1.46 & .64 & 1.43 & .57 & 1 \\
\hline
\end{tabular}




\begin{tabular}{llllll}
\hline Discretionary Power & 4.33 & 1.01 & 4.367 & 1.02 & .669 \\
\hline${ }^{\#}$ Aust $\mathrm{N}=1064{ }^{\#} \mathrm{UK} \mathrm{N}=725$ & & & & &
\end{tabular}

a Mean for first 5 variables: 1 = Strongly Disagree, through to $6=$ Strongly Agree

** Correlation is significant at the 0.001 level (2-tailed).

Table 5: Results from MANOVA: Testing for differences in Means for Nurses across public and private hospitals

\begin{tabular}{|c|c|c|c|c|c|}
\hline & \multicolumn{2}{|c|}{ Private $^{\#}$} & \multicolumn{2}{|c|}{ Public ${ }^{\# \#}$} & \multirow[b]{2}{*}{ F score } \\
\hline & Mean $^{a}$ & SD & Mean & SD & \\
\hline Supervisor-Subordinate Rel/ship & 4.77 & 1.05 & 4.34 & 1.03 & $64.725^{* *}$ \\
\hline Teamwork & 4.68 & .79 & 4.47 & .78 & $27.607 * *$ \\
\hline Role Ambiguity & 1.35 & .53 & 1.64 & .7 & $93.514^{* *}$ \\
\hline Discretionary Power & 4.47 & .97 & 4.09 & 1.05 & $55.938 * *$ \\
\hline
\end{tabular}

${ }^{\text {a }}$ Mean for first 5 variables: 1 = Strongly Disagree, through to $6=$ Strongly Agree

** Correlation is significant at the 0.001 level (2-tailed). 
Figure 1: Path Analysis: Relationships between Supervisor-Subordinate Relationship, Teamwork, Role Ambiguity and Discretionary Power

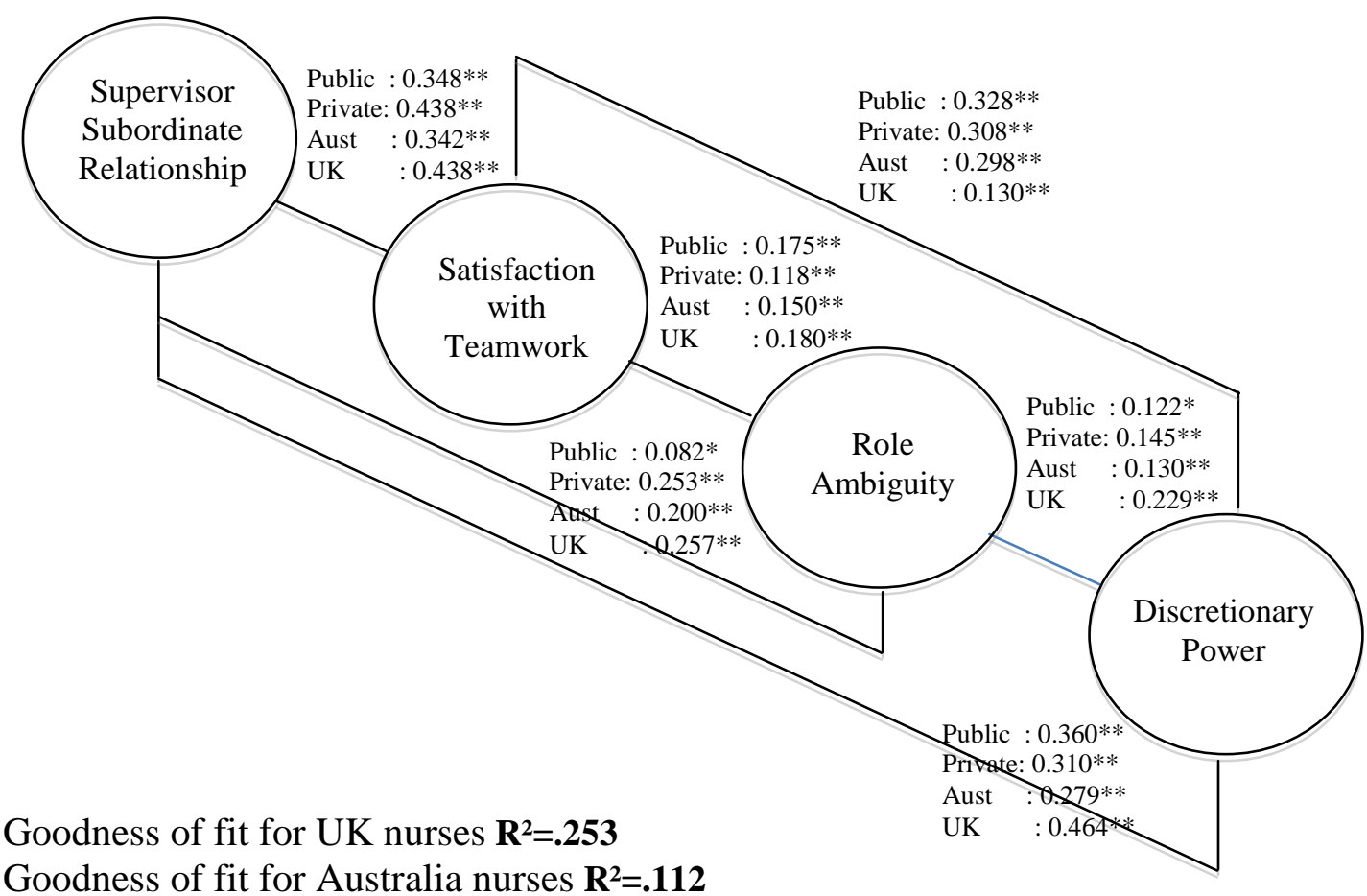

Goodness of fit for public sector nurses $\mathbf{R}^{2}=\mathbf{1 7 7}$

Goodness of fit for private sector nurses $\mathbf{R}^{2}=\mathbf{. 1 3 3}$ 